Special Issue of the 7th International Advances in Applied Physics and Materials Science (APMAS 2017)

\title{
Numerical Comparison of the Effect of Blade Material on Wind Turbine Efficiency
}

\author{
G. OzDAmar ${ }^{a, *}$, M. Mertcan ${ }^{b}$ And A. OzDAmar ${ }^{b}$ \\ ${ }^{a}$ Ege University, Graduate School of Natural and Applied Sciences, Department of Mechanical Engineering, \\ 35100 Izmir, Turkey \\ ${ }^{b}$ Ege University, Faculty of Engineering, Department of Mechanical Engineering, \\ 35100 Izmir, Turkey
}

\begin{abstract}
Wind energy, which is enormously important to protect the environment, can be converted into electricity by wind turbines. Wind turbines consist of a base, a tower, a generator, a gearbox, a hub and rotor blades. Horizontal wind turbines are designed with three blades to have higher efficiency. Wind turbine blade can be made of wood, steel, aluminum, carbon fiber-reinforced plastics and glass fiber-reinforced plastics. In this work it is aimed to study the effect of blade material on the wind turbine efficiency using numerical method. The commercial software ANSYS Fluent is used to calculate and compare the efficiencies of wind turbines with different blade materials. In the numerical analysis the flow is modelled as viscous, laminar and incompressible. Results show that the frictional effect on the hub bearing is bigger if a denser material is used. This effect reduces the efficiency of wind turbines.
\end{abstract}

DOI: 10.12693/APhysPolA.134.156

PACS/topics: environmental physics, blade material, efficiency of wind turbine, optimization, finite volume method, wind energy

\section{Introduction}

According to their exhaustibility the energy sources can be classified into two groups of exhaustible and inexhaustible energy sources. Inexhaustible energy sources are constantly renewed. In contrast to this, exhaustible energy sources like coal, natural gas, oil and nuclear energy are not replenished.

Inexhaustible, renewable energy sources can be classified, according to their origin, into three groups: Solar, Moon and Earth groups. The Moon is the source of tides. Tide power is converted into electricity by the tide power plants. The importance of the Earth, as the primary source, comes from geothermal energy. The geothermal energy power plants convert heat energy into the electricity. Considering the Sun, water-based, wind, sun rays and biomass energies originate from it.

Sun heats different regions of the atmosphere to different temperatures, which causes pressure gradients. These pressure gradients cause air streams from high pressure zones to low pressure zones. Movement of air affects the surface of the oceans by friction and generates water waves [1]. Movement of air in the form of wind is another type of renewable energy.

Wind energy can be converted into electricity by wind turbines. Figure 1 shows the power capacity of the installed turbines in the world, which has increased to 486.749 MW in 2016 [2]. Wind turbines consist of a tower, propellers, a gear box, a generator shaft and a generator, as the main components.

*corresponding author; e-mail: gokhan.ozdamar@ege.edu.tr

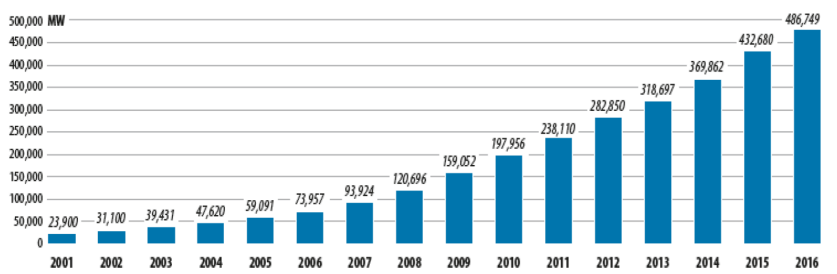

Fig. 1. Global cumulative installed wind capacity in 2011-2016 [2].

The kinetic energy of the wind is converted into mechanical energy at the turbine blade. The efficiency of a blade can reach the maximum value of $59.26 \%$, which is the Betz limit, if losses are neglected. One of the reasons why the efficiency of a wind turbine can not reach its ideal value is that the friction losses in the hub bearings depend on the material of the wind turbine blades.

In this study the effect of blade material on blade efficiency is analyzed numerically using the commercial software ANSYS Fluent, based on the finite volume method. In the literature, the effect of weight of materials on wind turbines has not been studied using this method. The purpose of this work is to fill this gap and then to put forward a method to use this effect in other areas.

\section{Theory}

The wind power that passes through the turbine is given by Eq. (1):

$$
P_{\mathrm{gw}}=0.5 C_{\mathrm{p}} \rho A V^{3}
$$

where $C_{\mathrm{p}}$, is power coefficient factor, $\rho$ is air density, $A$ is area swept by the turbine blades, and $V$ is the velocity of wind [3-7]. The power factor in Eq. (1) also depends 
on many other parameters, such as the loss caused by friction in the bearings, transmitting components, etc.

Frictional torque that occurs through the reverse direction of the movement of the wind turbine can be calculated by Eq. (2),

$$
M_{\mathrm{S}}=\mu F d / 2,
$$

where $M_{\mathrm{S}}$ is frictional torque, $d$ is radius of the roller and $F$ is radial load, which is the sum of the blade weights [8]. In order to investigate the effect of the blade material on the turbine efficiency, a blade with a diameter of $1 \mathrm{~m}$, as seen in Fig. 2, was selected in this study. Hub bearing radius was taken to be $d / 2=0.055 \mathrm{~m}$ and the dynamic viscosity of the lubricant is selected as $\mu=1$ Pas. The specific blade mass $\xi\left(\mathrm{kg} / \mathrm{m}^{2}\right)$ is defined as the total mass of blades per swept area. Depending on the chosen blade material, for $1 \mathrm{~m}$ long wind turbine blade the specific blade mass [9] and the torque values, calculated according to Eq. (2), are given in Table I.

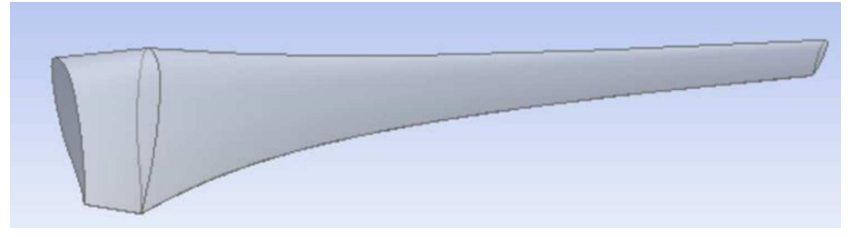

Fig. 2. Drawing of the investigated wind turbine blade. Blade radius $R=1 \mathrm{~m}$, number of blades $z=3$, profile type LS-1.

TABLE I

Parameters corresponding to various blade materials. A - glass and glass/carbon-epoxy, B - glass/polyester, C earlier glass/polyester with heavy flanges.

\begin{tabular}{l|c|c|c}
\hline \hline Wind turbine blade material & A & B & C \\
\hline Specific blade mass $\left[\mathrm{kg} / \mathrm{m}^{2}\right]$ & 0.3 & 1 & 1.7 \\
\hline Friction moment $[\mathrm{Nm}]$ & 0.5 & 1.69 & 2.88 \\
\hline Power coefficient & 0.41 & 0.39 & 0.37
\end{tabular}

\section{Numerical calculation}

In order to determine the effects of friction in the hub bearings, caused by blade weight, on the efficiency of the wind turbine, firstly, only the aerodynamics of the wind turbine blade has been numerically analyzed using the commercial ANSYS Fluent software based on the finite volume method.

Mesh of the blade and velocity contours are given in Fig. 3. As a result of numerical analysis, the torque value $M_{\mathrm{b}}$ is found to be $9.17 \mathrm{Nm}$ for one blade. By using three times the torque, the power coefficient $C_{\mathrm{p}}$ value is found to be 0.42 . In addition to that, the power factor is calculated by subtracting the values of the friction torque at the hub bearings of each material from the value for frictionless moment. These results are given in Table I.
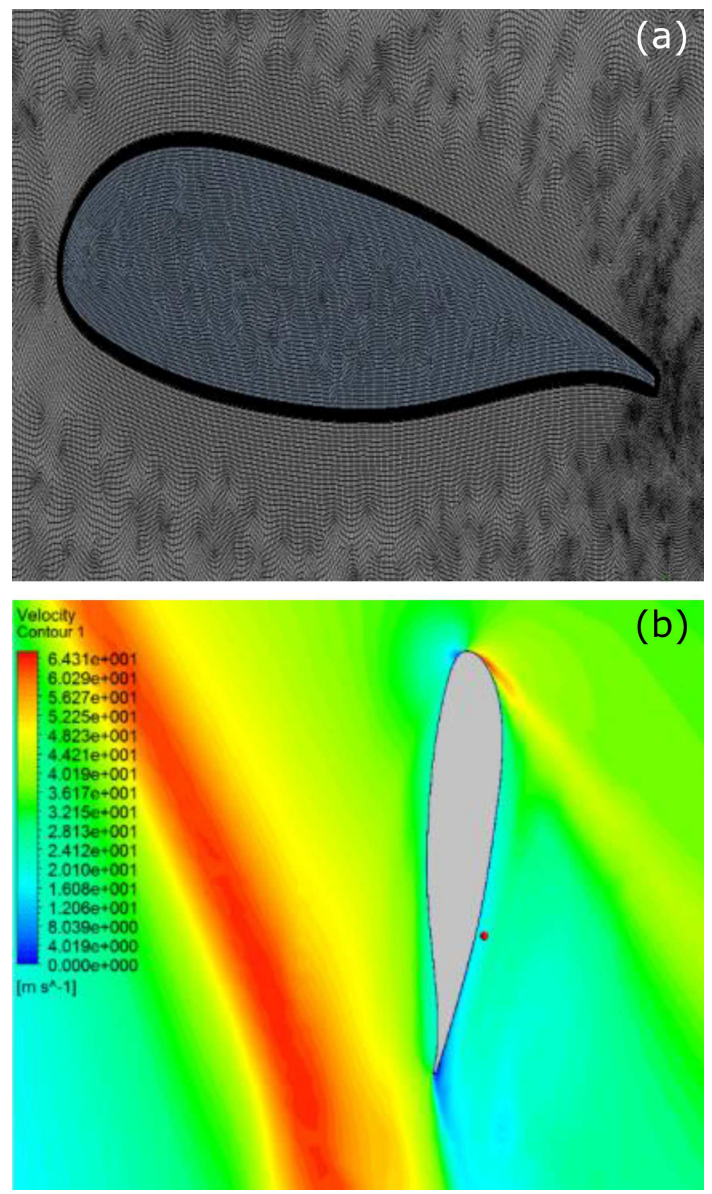

Fig. 3. Mesh (a), and velocity contours (b) of the wind turbine blades.

\section{Results and discussion}

As it is shown in Table I, if the friction in the hub bearings is not taken into account, the calculated power factor is $42 \%$. As a result of the change in the blade material, power factor obtains values of $41 \%$ for glass and glass/carbon-epoxy material, $39 \%$ for glass/polyester material and $37 \%$ for earlier glass/polyester material.

If the life of a wind turbine is considered to be 25 years, 1-5\% efficiency improvement due to the correctly selected blade material becomes highly important from the economic point of view. While specific blade mass $\xi$ increases, wind turbine efficiency $C_{\mathrm{p}}$ tends to decrease, as shown in Fig. 4.

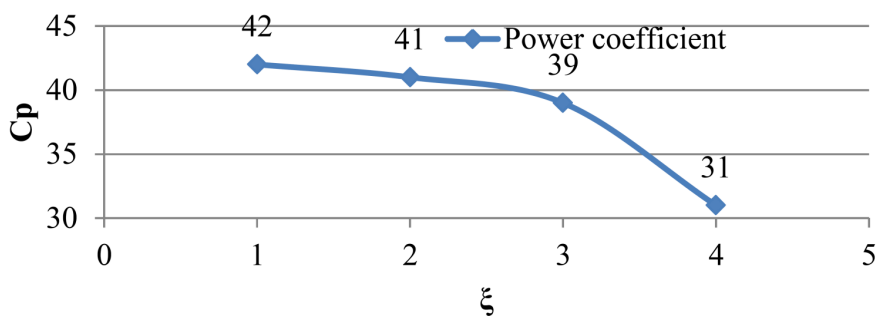

Fig. 4. Power coefficient vs. the specific blade mass. 
As a general conclusion, since blade material significantly influences the efficiency of the wind turbine, the selection of the blade material in wind turbines should be taken into account.

\section{References}

[1] G. Özdamar, M. Mut, Y. Pekbey, A. Özdamar, Dicle Uni. Müh. Fak. Müh. Der, 7-3-569-576 MD-16-050, 2016, (in Turkish).

[2] Global Wind Statistics 2016 (Date of Access: $24 / 01 / 2018)$.

[3] J. Zaragoza, J. Pou, A. Arias, C. Spiteri, E. Robles, S. Ceballos, Ren. Ener. 36(5), 1421 (2011).
[4] A. Hiramoto, Int. Symp. Wave Tidal Energy. Canterbury, England 73, 83 (1978).

[5] M. Cirrincione, M. Pucci, G. Vitale, Proced. IEEE Energy Convers. Congr. Expos. 49, 857 (2011).

[6] S. Heir, Grid integration of wind energy conversion systems, John Wiley and Sons Inc., New York 1998.

[7] E. Koç, Makina Elemanları, Cilt 2, Nobel Yayın Evi, 2010, (in Turkish).

[8] B. Muhando, T. Senjyu, H. Kinjo, T. Funabashi, IEEE Trans. Energy Convers., 24, 211 (2009).

[9] E. Hau, Wind Turbines, Fundamentals, Technologies, Application, Economics, Springer Science \& Business Media, Berlin 2005. 